\title{
Renal Artery Thrombosis following Lobectomy for Lung Cancer
}

\author{
Christos Asteriou Nikolaos Barbetakis Andreas Efstathiou \\ Athanassios Kleontas Christodoulos Tsilikas \\ Cardiothoracic Surgery Department, Theagenio Cancer Hospital, Thessaloniki, \\ Greece
}

\section{Key Words}

Lung cancer $\cdot$ Surgery $\cdot$ Renal $\cdot$ Arterial thrombosis

\begin{abstract}
Acute renal arterial thrombosis is a rare but very urgent situation demanding immediate treatment. It is characterized by unspecific symptomatology which often misleads the clinicians. As a result, precious time can be lost until the correct diagnosis is reached. The case of a 53-year-old female who underwent a left upper lobectomy for lung cancer is presented. On the third postoperative day, the patient began to complain of a flank pain located at the lower side of the left hemithorax and the nearby lumbar area. A renal arterial thrombosis was finally diagnosed and subcutaneous low molecular weight heparin was started immediately. The patient was discharged two weeks later and anticoagulation therapy with warfarin was given. Six months later, renal function remains satisfying and the patient is free of any symptoms. This is probably the first case in English literature of renal arterial thrombosis following lobectomy for lung cancer.
\end{abstract}

\section{Introduction}

Renal arterial thrombosis is a very unusual complication following major thoracic operations. The incidence of renal infarction in an autopsy study was $1.4 \%$, whereas clinical diagnosis was made in only $0.014 \%$ of the studied patients [1]. Cardiac diseases and arrhythmias are the most common causes [2]. Lack of specific signs and symptoms complicates the differential diagnosis. The clinical manifestations of renal artery thrombosis vary, depending on whether the occlusion affects both renal arteries or not. Delay of the correct diagnosis may prove disastrous for the patient. Our case is probably the first one in English literature describing a patient with unilateral renal artery thrombosis after lobectomy for lung cancer. 


\begin{tabular}{|c|c|c|c|}
\hline $\begin{array}{l}\text { Cose Reports in } \\
\text { Ona.ayly }\end{array}$ & $\begin{array}{l}\text { Case Rep Oncol 2010;3:208-211 } \\
\text { D0I: } 10.1159 / 000314838\end{array}$ & Published online: July 3, 2010 & $\begin{array}{l}\text { @ } 2010 \text { S. Karger AG, Basel } \\
\text { ISSN 1662-6575 } \\
\text { www.karger.com/cro }\end{array}$ \\
\hline
\end{tabular}

\section{Case Report}

A 53-year-old female patient was admitted to our hospital with the diagnosis of lung cancer. Her medical history was clear, except that she was a social drinker and smoker (3-4 glasses of wine/week, 5 cigarettes/day for 25 years). Physical examination and blood test analysis were normal, and cardiac function was found to be excellent. The preoperative transbronchial needle aspiration cytology revealed an adenocarcinoma in the left upper lobe. Computed tomography (CT) of the thorax, abdomen and brain revealed nothing apart from a mass located in the left upper lobe, $2 \mathrm{~cm}$ in diameter. Bone scan was negative.

The patient received a formal left upper lobectomy in combination with mediastinal lymph node sampling. No complications were observed during the operation, and the immediate postoperative period was straightforward until the third postoperative day, when she began to complain of a flank pain located at the lower side of the left hemithorax and the nearby lumbar area. The pain was not affected by respiratory movements and position changes, and it was continuous without radiation. Body temperature as well as the rest of the physical examination were normal. Laboratory data showed a minor elevation of white blood cell count $\left(12,500 \mathrm{cells} / \mathrm{mm}^{3}\right)$ and lactate dehydrogenase (371 IU/l). Initially, thoracotomy trauma and draining tubes were considered responsible for the pain. Consequently, the patient was treated with painkillers and anti-inflammatory agents. Despite the medication given, pain persisted for the next $24 \mathrm{~h}$ without any changes. An upper abdomen ultrasound scan was performed combined with a chest X-ray revealing nothing that could explain the condition. Contrast-enhanced CT of the thorax and upper abdomen ( $\underline{\text { fig. } 1 \text { ) }}$ ) was then administered to elucidate the diagnostic dilemma. Occlusion of the left main renal artery was revealed. Subcutaneous low molecular weight heparin 10,000 IU was started immediately. An expert nephrologist was called in order to manage the problem. However, precious time was already lost and further therapy with thrombolytics did not offer significant improvement, since the left kidney was considered already nonfunctioning. Renal function remained normal due to the right kidney. The levels of blood urea nitrogen and creatinine did not show remarkable elevation compared with the preoperative ones (urea: $33 \rightarrow 41$ $\mathrm{mg} / \mathrm{dl}$, creatinine: $0.71 \rightarrow 0.83 \mathrm{mg} / \mathrm{dl}$ ). The patient was discharged two weeks after the operation and anticoagulation therapy with warfarin was given. Six months later, renal function remains satisfying and the patient is free of any symptoms.

\section{Discussion}

It is of crucial importance for acute renal artery thrombosis, although it is an uncommon situation, to be diagnosed early. In the vast majority of the cases, however, significant delay is the rule, causing irreversible damage to the kidney. The clinical presentations of renal arterial thrombosis are not specific for the disease and usually include flank pain originating from the ipsilateral lumbar area, accompanied by fever, nausea and vomiting. Physical examination may sometimes reveal costovertebral angle tenderness. Acute hypertension is also possible to coexist [3]. Anuria or oliguria combined with proteinuria or hematuria are findings indicating bilateral renal artery occlusion. Blood tests are not apt to establish an accurate diagnosis because of lack in sensitivity and specificity.

Common causes of renal artery occlusion include congestive heart failure, atrial fibrillation, and valvular or ischemic heart disease. Moreover, trauma, clotting disorders, cancer and some rare hereditary diseases are also mentioned. Differential diagnosis is extremely difficult. Ureterolithiasis, pyelonephritis, acute myocardial infarction and acute cholecystitis must be excluded [4]. Plain X-ray and ultrasonography can be significantly helpful, but the final diagnosis is usually determined by contrast-enhanced CT. Invasive diagnostic tools such as renal artery angiography are not without complications.

In our case, the diagnosis was delayed and as a result the left kidney lost its function. Given that the patient was free of cardiac diseases and clotting disorders, lung cancer could have been the cause for renal arterial thrombosis. Paraneoplastic thrombosis as the etiopathogenic mechanism is a reasonable explanation [5]. Although the patient was 


\begin{tabular}{|c|c|c|c|}
\hline $\begin{array}{c}\text { Cose Reports in } \\
\text { Ona.doty }\end{array}$ & $\begin{array}{l}\text { Case Rep Oncol 2010;3:208-211 } \\
\text { D0I: } 10.1159 / 000314838\end{array}$ & Published online: July 3, 2010 & $\begin{array}{l}\text { @ } 2010 \text { S. Karger AG, Basel } \\
\text { ISSN 1662-6575 } \\
\text { www.karger.com/cro }\end{array}$ \\
\hline
\end{tabular}

receiving subcutaneous low molecular weight heparin 3,500 IU from the first postoperative day, this very serious complication did happen. Diagnosis was reached incidentally with the help of contrast-enhanced CT, which seems to be the gold standard for renal artery occlusion diagnosis [6]. Therapy in acute renal thrombosis typically consists of low molecular weight heparin in the acute phase, followed by warfarin. The value of antiplatelets is still under study. Because of the high risk for more thromboembolic complications in these patients it is advisable that the anticoagulation treatment should be continued, and a careful follow-up is mandatory [7].

\section{Conclusions}

In conclusion, renal arterial thrombosis is a rare and serious condition, which should be diagnosed early. Nonspecific symptomatology complicates the differential diagnosis and a high level of suspicion is required in order to not lose precious time. Acute renal occlusion may occur in previously healthy individuals. If lumbar flank pain appears and all other possible diagnoses are excluded, contrast-enhanced CT should be considered. Apart from the usual causes, the clinician should keep in mind this extremely uncommon case, which may be the first one described in English literature.

Fig. 1. Contrast-enhanced CT showing a filling defect in the left renal artery (red arrow).

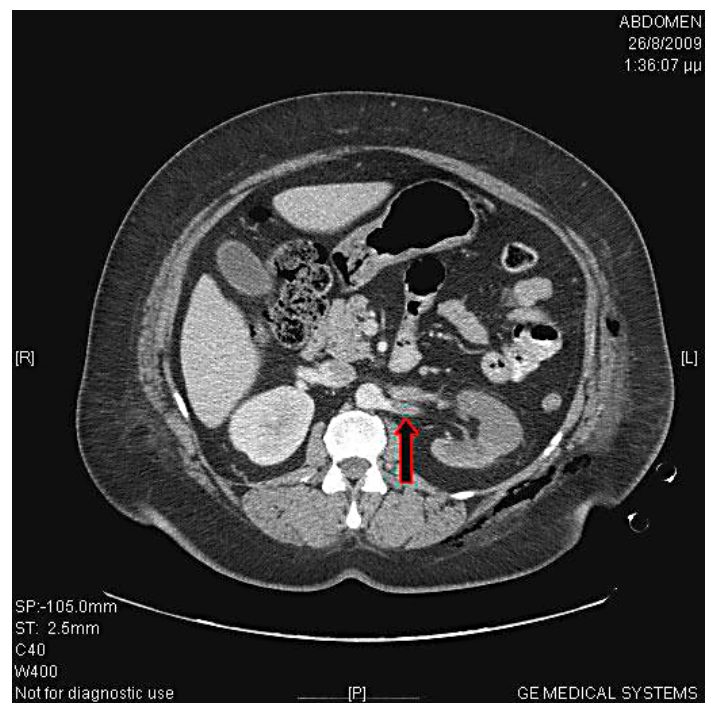




\section{References}

1 Abreu S, Arruda H, Cury J: Concomitant renal and splenic infarction. Int Braz J Urol 2000;26:526-527.

2 Lessman RK, Johnson SF, Coburn JW, Kaufman JJ: Renal artery embolism, clinical features and long-term follow-up of 17 cases. Ann Intern Med 1978;89:477-482.

-3 Fay MF, Nicholls MG, Richards AM: A man with severe, transient hypertension due to acute renal infarction. J Hum Hypertens 1999;13:343-344.

-4 Fu ZF, Zhang ZG, Liu XM: A rare case of acute renal infarction due to idiopathic renal arterial thrombosis. Chin Med J 2008;121:185-187.

5 Puglionisi A, Picciocchi A, Lemmo G, Cascone C, Intonti F, Breccia PA, Danza F: Cavoauricular thrombectomy under extracorporeal circulation and right superior lobectomy for paraneoplastic thrombosis in a case of lung cancer. J Chir (Paris) 1984;121:673-679.

6 Amilineni V, Lackner DF, Morse WS, Srinivas N: Contrast-enhanced CT for acute flank pain caused by acute renal artery occlusion. AJR 2000;174:105-106.

7 Mark G, Rainer H, Marshall S: Renal artery embolism. Clinical features and therapeutic options. J Urol 1992;147:567-572. 